\title{
OrganOGÉNESIS Y EMBRIOGÉNESIS SOMÁTICA DE BEAUCARNEA INERMIS (ASPARAGACEAE), UNA ESPECIE AMENAZADA DEL NORESTE DE MÉXICO
}

\author{
Susana Guillén ${ }^{1}$, Alejandro Martínez-Palacios ${ }^{1,3}$, Herlinda Martínez ${ }^{1}$ \\ y José Guadalupe Martínez-Ávalos ${ }^{2}$ \\ ${ }^{1}$ Instituto de Investigaciones Agropecuarias y Forestales, Universidad Michoacana de San Nicolás de Hidalgo, \\ Tarímbaro, Michoacán, México \\ ${ }^{2}$ Instituto de Ecología Aplicada, Universidad de Autónoma de Tamaulipas, Ciudad Victoria, Tamaulipas, México \\ ${ }^{3}$ Autor para la correspondencia: apalacios56@gmail.com
}

\begin{abstract}
Resumen: Cinco tipos de explantes de plantas de 90 días de Beaucarnea inermis generadas a partir de la germinación in vitro de semillas, fueron utilizadas para la propagación in vitro a través de la organogénesis y embriogénesis somática. Para la embriogénesis somática, se utilizó medio B5 en segmento basal de hoja y en callo derivado de ápice de brote, generando una media de 2.2 y 3.6 embriones, respectivamente; ambos en presencia de $0.5 \mathrm{mg} \mathrm{L}^{-1}$ cinetina $+2 \mathrm{mg} \mathrm{L}^{-1}$ de ácido 2,4-diclorofenoxiacético. En ápice de tallo se generaron 6.8 embriones en promedio, con $0.5 \mathrm{mg} \mathrm{L}^{-1}$ cinetina $+4 \mathrm{mg} \mathrm{L}^{-1}$ de ácido 2,4-diclorofenoxiacético. La presencia de luz y ácido 2,4-diclorofenoxiacético en callo derivó a la producción de raíz. Para la organogénesis se usó el medio MS; en segmento basal de hoja se generaron 2.8 brotes adventicios en presencia de $6 \mathrm{mg} \mathrm{L}^{-1}$ de 6 -benciladenina $+0.5 \mathrm{mg} \mathrm{L} \mathrm{L}^{-1}$ de ácido naftalen-acético. El explante de callo y ápice de tallo generó 11.3 y 15.7 brotes, respectivamente; ambos en presencia de 2 $\mathrm{mg} \mathrm{L}^{-1}$ de 6-benciladenina. Los embriones somáticos germinaron y se desarrollaron en MS basal. La formación de raíz in vitro en brotes individualizados se incrementó cuando al medio MS se adicionó $1 \mathrm{mg} \mathrm{L}^{-1}$ de ácido indol-3-butírico. Se registró hasta 100\% de supervivencia 90 días después del trasplante bajo condiciones de invernadero. Las dos vías generaron el engrosamiento típico de la base del tallo. En este estudio se establece un sistema eficiente de micropropagación por diversas vías y herramientas para generar plantas comerciales e indirectamente reducir la presión de la sobre colecta en poblaciones silvestres.
\end{abstract}

Palabras clave: micropropagación, regulador del crecimiento, soyate, supervivencia.

\begin{abstract}
Somatic embryogenesis and organogenesis were induced through five explant types of Beaucarnea inermis plants 90 days old and generated from in vitro germination. For somatic embryogenesis, B5 medium was used in basal leaf segment and callus derived from stem apex and 2.2 and 3.6 embryos were generated, respectively; both in the presence of $0.5 \mathrm{mg} \mathrm{L}^{-1} \mathrm{kinetin}+$ $2 \mathrm{mg} \mathrm{L}^{-1}$ 2,4-dichlorophenoxyacetic acid. In stem apex a mean of 6.8 embryos were registered with $0.5 \mathrm{mg} \mathrm{L}^{-1} \mathrm{kinetin}+4 \mathrm{mg} \mathrm{L}^{-1}$ 2,4-dichlorophenoxyacetic acid. The combination of light and 2,4-dichlorophenoxyacetic acid in callus induced root formation. For somatic organogenesis, MS medium was used in basal leaf segment and 2.8 adventitious shoots were generated in the presence of $6 \mathrm{mg} \mathrm{L}^{-1}$ benzyladenine $+0.5 \mathrm{mg} \mathrm{L}^{-1}$ naphthalen-1-acetic acid. The callus and stem apex generated 11.3 and 15.7 shoots, respectively; both in the presence of $2 \mathrm{mg} \mathrm{L}^{-1}$ benzyladenine. Somatic embryos germinated and developed into plantlets in basal MS media. In vitro root formation in individualized shoots incremented when $1 \mathrm{mg} \mathrm{L}^{-1}$ of indol-3 butyric acid was added to the medium. One hundred percent survivorship was registered 90 days after transplanted under greenhouse conditions. Both propagation methods produced the typical stem thickening. In this study, an efficient micropropagation protocol was established as an alternative to produce ornamental plants and indirectly as a way to reduce the exploitation of wild populations.
\end{abstract}

Key Words: Growth regulator, micropropagation, soyate, survival.

$\boldsymbol{B}$ eaucarnea inermis (Asparagaceae) es una monocotiledónea, dioica, arborescente de 5 a $13 \mathrm{~m}$ de altura, con la base del tronco globosa y hojas curvadas, conocida localmente como "soyate". Presenta un tallo con la base del tronco globosa, angostándose hacia el cuello; las hojas son largas y lineares, formando rosetas en los extremos de las ramas; las inflorescencias son panículas muy vistosas, con flores blancas pequeñas y frutos de tres alas (Irish y Irish, 
2000). Existe poca información bien documentada acerca de la distribución geográfica y del estado poblacional de $B$. inermis; sin embargo, algunos reportes han indicado que es una planta endémica de los estados de San Luis Potosí, Tamaulipas y Veracruz. Muestra mayor abundancia en las selvas bajas caducifolias del estado de Tamaulipas. Aunque se han realizado pocos estudios poblacionales en torno a las especies del género Beaucarnea (Pérez-Farrera et al., 2012) se sabe que las poblaciones de $B$. inermis son muy pequeñas, se han estimado de 60 a 300 ind. ha ${ }^{-1}$ (Mora, 2005[AR1]; Hernández et al., 2012). Los adultos llegan a producir 5,000 flores por inflorescencia (Lemaire, 1861), esta cantidad de flores podría suponer un alto número de semillas, nuevos individuos y poblaciones en equilibrio. Sin embargo, el reclutamiento de nuevos individuos no sucede por diversas causas, como es el cambio del uso de suelo y el continuo saqueo de semillas y plantas de tallas de 2 m o más de altura (Hernández, 1993). Existen estudios demográficos realizados de $B$. inermis que indican un desequilibrio en su dinámica poblacional debido a que el número de las categorías juveniles es bajo, lo que es un indicador de que la especie tiene bajas tasas de reclutamiento; sin embargo, estos estudios no han sido documentados.

Por otra parte, debido al uso ornamental que tienen todas las especies del género Beaucarnea como plantas de interior y exterior, su demanda en el mercado nacional e internacional es muy alta. Los costos por planta con tallo globoso en su base y longitudes altas se han registrado hasta en $\$ 700.00$ US en Alemania, Estados Unidos y Holanda (Samyn, 1997). En las últimas dos décadas, en el mercado nacional muchas plantas del género se han comercializado por costos similares, teniendo como destino casas residenciales y restaurantes de lujo en diferentes estados de la República Mexicana. Con la finalidad de satisfacer la creciente demanda de plantas de Beaucarnea sp. (llamadas "patas de elefante") se han establecido viveros comerciales; sin embargo, el material vegetal usado en la propagación proviene en su mayor parte de colectas ilegales en poblaciones silvestres en las que las comunidades campesinas no obtienen grandes beneficios. Hernández (1993) y Cardel et al. (1997) mencionan que la colecta de semillas de las especies de Beaucarnea deja pocos recursos económicos a los lugareños, siendo los intermediarios y comerciantes los que registran el mayor beneficio monetario. Esta situación propicia una mayor presión sobre las poblaciones silvestres, lo que agrava su estado de vulnerabilidad (Hernández, 1993). Por esta razón, todo el género Beaucarnea es considerado como amenazado, según la NOM-059 (SEMARNAT, 2010).

En especies de zonas áridas, como Agaváceas y Nolináceas, con problemas de conservación, Golubov et al. (2007) propusieron la propagación masiva de plantas mediante semillas colectadas en poblaciones silvestres, debido a que de esta manera se puede conservar una elevada diversidad genética. Otra ventaja de propagar plantas usando semillas es que, estas últimas tienen la totipotencialidad de ser conservadas por décadas manteniendo su viabilidad si son almacenadas bajo condiciones ambientales adecuadas. En Agave cupreata, A. victoriae-reginae y Beaucarnea recurvata se tuvieron altos porcentajes de germinación en semillas almacenadas en condiciones de temperatura y humedad relativa bajas (Golubov et al., 2007; Martínez-Palacios y Eguiarte, 2011; Martínez-Palacios, 2012). Sin embargo, antes de considerar como una alternativa de conservación la propagación mediante semillas, se debe tomar en cuenta la viabilidad del sistema al considerar las características fisiológicas de cada especie (Golubov et al., 2007). En el caso de las especies del género Beaucarnea, por si sola, la propagación por medio de semillas para desarrollar plantas adultas y comercializarlas sería una opción con la que no se alcanzarían a cubrir las demandas, debido a que sus especies son de lento crecimiento (Hernández, 1993). Al respecto, se ha mencionado que los individuos de Beaucarnea inermis cultivados in situ, alcanzan su estado reproductivo en un periodo que va de 20 a 30 años de edad, y que en experimentos establecidos en plantaciones sobre suelos húmedos, en regiones aledañas a las poblaciones silvestres donde las condiciones son más favorables, los individuos alcanzan tallas mayores a 60 centímetros de diámetro de la base del tallo y de 250 a 350 centímetros de altura en un periodo de 12 años. La propagación vía semillas in situ es la mejor alternativa de conservación, debido a que esto implica conservación de diversidad genética; sin embargo, es necesaria la aplicación de métodos ex situ que se complementen las estrategias de conservación.

Desde la década de 1960, la formulación del medio de cultivo MS desarrollado por Murashige y Skoog (1962) y, el mejoramiento de las técnicas de cultivos vegetales in vitro, propiciaron el incremento de estudios realizados con la finalidad de resolver algunos problemas de biología básica en especies agrícolas, hortícolas y forestales (Thorpe, 2006), en las que se buscaba establecer patrones celulares, generación de sistemas de multiplicación masiva, clonación, mejoramiento, plantas libres de virus así como conservación y almacenamiento de germoplasma, entre otros (Murashige, 1978; Thorpe, 2006). El uso de las técnicas de cultivo in vitro con fines de conservación ha cobrado poco a poco importancia; de acuerdo a Sarasan et al. (2006), en los años de 1995 a 2005, aún eran muy pocos los trabajos existentes, al respecto. Una de las ventajas del cultivo in vitro, radica en que es un proceso que no requiere de nuevo material biológico de campo cuando ya se tiene tejido u órganos bajo reproducción continua, por lo que el cultivo de tejidos vegetales es una herramienta que se puede aplicar como alternativa de conservación. En México, entre los primeros trabajos de micropropagación en especies amenazadas está el de Mammillaria san-angelensis, especie endémica de El pedregal de San Ángel, ciudad de México, para la cual se usaron como explantes segmentos de tallos con yemas axilares para inducir la formación de múltiples brotes al adi- 
cionar la citocinina benciladenina (BA) al medio de cultivo (Martínez-Vázquez y Rubluo, 1989; Rubluo et al., 1993). La BA también se utilizó en la multiplicación in vitro de orquídeas en peligro de extinción, donde además de inducir la germinación asimbiótica en tejidos somáticos generó múltiples brotes (Rubluo et al., 1993). En este estudio se generaron plantas que fueron introducidas en su ambiente natural.

Existen pocos trabajos de micropropagación realizados con especies del género Beaucarnea. Por ejemplo, en $B$. recurvata, $B$. gracilis y $B$. goldmanii se indujo la organogénesis somática a partir de plántulas a las que se les escindieron las hojas y raíces pero conservando el ápice meristemático (ápices de tallo) y adicionando BA al medio de cultivo (Samyn, 1997; Osorio-Rosales y Mata-Rosas, 2005; Reyes et al., 2013). No hay antecedentes de algún trabajo de micropropagación realizado con $B$. inermis; un estudio de este tipo es necesario para complementar la información disponible al momento, con la finalidad de generar un sistema eficiente que pueda ser aplicado a un mayor número de especies que tengan los mismos problemas de conservación y con características de desarrollo similares.

El objetivo del presente trabajo fue establecer métodos eficientes de propagación masiva que puedan ser utilizados en la industria hortícola como coadyuvante en la disminución de la presión de la sobre colecta de semillas y plantas de poblaciones silvestres de Beaucarnea inermis, especie amenazada de extinción. Por lo anterior, se evaluó la micropropagación vía organogénesis y embriogénesis somática directa e indirecta a partir de ápices de tallos y segmentos de hojas. Además de evaluar la aclimatación y supervivencia en invernadero de las plantas generadas a partir del cultivo in vitro.

\section{Materiales y métodos}

Colecta de semillas. En 2009 se tomaron los frutos maduros de seis plantas de Beaucarnea inermis, seleccionadas al azar, en la selva baja caducifolia del Municipio de Ocampo, Tamaulipas, México. En el laboratorio, se abrieron los frutos y se les extrajeron las semillas, cada fruto contenía entre dos y tres semillas. Las semillas se limpiaron y almacenaron en condiciones de refrigeración dentro bolsas de papel hasta su posterior uso.

Germinación in vitro y condiciones de cultivo. Con la finalidad de obtener explantes asépticos para la inducción de embriogénesis y organogénesis, se obtuvieron plántulas generadas a partir de la germinación in vitro. Por lo que en frascos de vidrio de $125 \mathrm{ml}$ de capacidad, con $30 \mathrm{ml}$ de medio de cultivo MS basal (Murashige y Skoog, 1962) en su interior, se sembraron seis semillas; en total se tenían 144 semillas en 24 frascos. Antes de sembrar las semillas en el medio, se desinfectaron: primero se lavaron con agua co- rriente por 30 min, después se sumergieron en alcohol etílico al $70 \%$ por un min y finalmente, con una solución al $30 \%$ $\mathrm{v} / \mathrm{v}$ de blanqueador comercial (hipoclorito de sodio, $6 \%$ de cloro activo) durante $30 \mathrm{~min}$. Con la finalidad de eliminar trazas de las soluciones utilizadas durante la desinfección, las semillas se enjuagaron en tres ocasiones con agua destilada esterilizada.

El medio basal MS fue suplementado con $100 \mathrm{mg} \mathrm{L}^{-1}$ de mio-inositol, $4 \mathrm{mg} \mathrm{L}^{-1}$ de tiamina- $\mathrm{HCl}, 30 \mathrm{~g} \mathrm{~L}^{-1}$ de sacarosa y $8 \mathrm{~g} \mathrm{~L}^{-1}$ de agar (agar-agar Sigma A-1296, Plant Tissue Culture grade). Antes de adicionar el agar, el $\mathrm{pH}$ del medio fue ajustado a 5.7 con $\mathrm{KOH}$ y/o $\mathrm{HCl} 0.1 \mathrm{~N}$, con un potenciómetro digital (Fisher Scientific, AB15, E.U.). Los medios de cultivo fueron esterilizados en autoclave vertical (Felisa FE399), a $1.7 \mathrm{~kg} \mathrm{~cm}^{-2}, 120{ }^{\circ} \mathrm{C}$ por $15 \mathrm{~min}$. Los frascos con las semillas cultivadas fueron incubados bajo las condiciones descritas abajo. La germinación se estandarizó a los 30 días.

En todos los experimentos realizados en esta investigación se utilizaron frascos con las mismas características de capacidad (125 ml) y contenido de medio de cultivo (30 ml); asimismo, casi todos los cultivos fueron incubados bajo las mismas condiciones ambientales (temperatura de $27{ }^{\circ} \mathrm{C}$, fotoperiodo de $16 \mathrm{~h}$ luz con una intensidad de $45 \mu \mathrm{mol} \mathrm{m}{ }^{-2}$ $\mathrm{s}^{-1}$ y $8 \mathrm{~h}$ de oscuridad); la luz fue suministrada por lámparas de luz blanca-fría fluorescente. Si las condiciones de incubación son diferentes, se señala a lo largo del texto.

Explantes utilizados. Cuando las plántulas generadas in vitro alcanzaron 90 días de edad se disectaron y de las hojas desprendidas se tomaron tres tipos de explantes: (1) el ápice, (2) la parte media, y (3) la base, que es el segmento que sujeta a la hoja alrededor del tallo de la planta; cada segmento tenía aproximadamente $1 \mathrm{~cm}$ de longitud. El otro tipo de explante utilizado fue (4) el ápice de tallo $(3 \times 3-5 \mathrm{~mm}$ de largo), que resultó de retirar las raíces y hojas de la planta. Además, se utilizaron (5) fragmentos de callo (aproximadamente $1 \mathrm{~cm}^{3}$ ) que se generaron del cultivo inicial de ápices de tallo y de 3 a 4 subcultivos posteriores cada seis semanas. Para la generación del callo se usaron, de manera independiente, dos medios de cultivo diferentes, cada uno con una finalidad específica: para inducción de organogénesis se uso el medio MS con $2 \mathrm{mg} \mathrm{L}^{-1}$ de 6-benciladenina (BA), y para inducción de embriogénesis somática se utilizó el medio B5 (Gamborg et al., 1968) con $0.5 \mathrm{mg} \mathrm{L}^{-1}$ de cinetina (KIN) y $4 \mathrm{mg} \mathrm{L}^{-1}$ de ácido 2,4-diclorofenoxiacético (2,4-D). Ambos medios fueron suplementados con los mismos nutrimentos y en las mismas cantidades del medio MS utilizado para la germinación in vitro.

Embriogénesis somática indirecta. Los cinco tipos de explantes fueron cultivados de manera independiente en medio B5 modificado con diferentes concentraciones de diversas fitohormonas. Los segmentos de hoja se cultivaron en 
presencia de $0,0.5,1,2,4$ y $8 \mathrm{mg} \mathrm{L}^{-1}$ de 2,4 -D en combinación con $0,0.5$ y $1 \mathrm{mg} \mathrm{L}^{-1}$ de $\mathrm{KIN}$, teniendo un total de 18 tratamientos para cada tipo de explante de hoja; cada tratamiento con seis réplicas; además, por réplica (frasco) se sembraron dos segmentos. Se probaron dos fotoperiodos durante la incubación: (1) 16 h luz y 8 h oscuridad y (2) 24 h oscuridad. Los frascos se mantuvieron en cultivo por 24 semanas.

Los resultados previos obtenidos en hoja, donde se formaron raíces adventicias en fotoperiodo con luz y embriones adventicios en fotoperiodo de oscuridad, permitieron decidir que los siguientes cultivos se incubaran bajo condiciones de oscuridad total.

Los ápices de tallo se cultivaron en medio modificado con 2, 4, 6 y $8 \mathrm{mg} \mathrm{L}^{-1}$ de 2,4-D en combinación con 0 y $0.5 \mathrm{mg} \mathrm{L}^{-1}$ de KIN, teniendo ocho tratamientos con cuatro réplicas y dos explantes por frasco de cultivo, incubados en condiciones de oscuridad por 24 semanas.

Los fragmentos de callo se cultivaron en presencia de $2 \mathrm{mg}$ $\mathrm{L}^{-1}$ de 2,4-D y $0.5 \mathrm{mg} \mathrm{L}^{-1}$ de KIN, con un control sin hormonas y, además, se exploró el efecto de la sacarosa, por lo que se probaron las concentraciones 40, 60 y $80 \mathrm{~g} \mathrm{~L}^{-1}$ [AR2]. Cada tratamiento con 12 repeticiones incubado en oscuridad durante 12 semanas.

Para la evaluación del número de embriones somáticos producidos en los diferentes tratamientos, se realizaron conteos de las estructuras embrionarias surgidas en la superficie del callo. También se estimó la proliferación de callo en volumen sobre la superficie del medio de cultivo, por lo que se establecieron las siguientes categorías de evaluación: +++ $\geq 2 \mathrm{~cm}^{3} ;++=0.5-1.9 \mathrm{~cm}^{3} ;+:<0.5 \mathrm{~cm}^{3}$. Previo al conteo y las estimaciones, cada fragmento de callo fue depositado en una caja de Petri de $100 \times 15 \mathrm{~mm}$, estéril y desechable para evitar su contaminación. Las observaciones se hicieron con ayuda de una lupa y un microscopio estereoscópico marca Zeiss Stemi 2000[AR3] (E.U.), siguiendo el método utilizado por Martínez-Palacios et al. (2003) en Agave victoriae-reginae. Terminadas las observaciones, los explantes se regresaron a los frascos de donde fueron extraídos.

Organogénesis indirecta y directa. Los cinco tipos de explantes fueron cultivados de manera independiente en medio MS modificado con diferentes concentraciones de fitohormonas. Los tres tipos de explantes de hoja se utilizaron para inducir la organogénesis indirecta, por lo que se cultivaron en medio modificado con $0,0.1$ y $0.5 \mathrm{mg} \mathrm{L}^{-1}$ de ácido naftalen-acético (ANA) en combinación con 0, 2, 4 y 6 mg $\mathrm{L}^{-1}$ de $\mathrm{BA}$, teniendo 12 tratamientos con seis réplicas cada uno y en cada réplica se cultivaron dos segmentos. La evaluación se realizó a las 22 semanas desde el cultivo.

Los ápices de tallo se utilizaron para inducir organogénesis directa y se cultivaron en medio modificado con BA, probando las concentraciones $0,2,4$ y $8 \mathrm{mg} \mathrm{L}^{-1}$. Cada tratamiento con 15 repeticiones y en cada una se cultivó un explante. La evaluación se realizó a las ocho semanas de cultivo.

Los fragmentos de callo fueron usados para explorar la inducción de brotes adventicios, por lo que se cultivaron en medio modificado con 2 y $3 \mathrm{mg} \mathrm{L}^{-1}$ de BA en combinación con 0 y $0.1 \mathrm{mg} \mathrm{L}^{-1}$ de ANA, y su réplica sin fitohormonas. La evaluación se realizó a las ocho semanas posteriores al cultivo. La cantidad de callo por la vía organogénica se estimó de la misma forma que se describió para la embriogénesis somática.

Germinación de embriones somáticos. Los embriones somáticos se separaron del callo inductor y se subcultivaron en medio B5 basal para inducir la germinación y el desarrollo de plántulas. Los cultivos se incubaron durante 45 días, los primeros 15 días se mantuvieron a una intensidad luminosa de $16 \mu \mathrm{mol} \mathrm{m}^{-2} \mathrm{~s}^{-1}$, incrementándose cada 15 días a 45 y $80 \mu \mathrm{mol} \mathrm{m} \mathrm{m}^{-2} \mathrm{~s}^{-1}$.

Enraizamiento in vitro de brotes adventicios. Los brotes generados a través de la organogénesis somática se individualizaron y se cultivaron en medio MS modificado con $0,0.5$ y $1 \mathrm{mg} \mathrm{L}^{-1}$ de ácido indol-3-butírico (IBA), incubados por 60 días bajo un fotoperiodo de $16 \mathrm{~h}$ luz, los primeros 30 días a una intensidad luminosa de $45 \mu \mathrm{mol} \mathrm{m} \mathrm{m}^{-2} \mathrm{~s}^{-1}$, incrementando a $80 \mu \mathrm{mol} \mathrm{m}^{-2} \mathrm{~s}^{-1}$ los últimos 30 días. Para evaluar el enraizamiento, se midió y sumó la longitud de todas las raíces de cada planta.

Establecimiento ex vitro de plántulas en condiciones de invernadero. Las plántulas derivadas de la embriogénesis somática y de la organogénesis se establecieron en un invernadero. Sin embargo, por haber un desfase en los tiempo de producción solo se evaluó la supervivencia de las plántulas derivadas de la organogénesis directa sometidas a diferentes tratamientos de enraizamiento (control y con AIB[AR4]). Se seleccionaron 81 plántulas enraizadas con características morfológicas similares; se lavaron en agua corriente para eliminar los restos del medio de cultivo y después se sembraron en charolas que contenían una mezcla de sustrato estéril (en autoclave a $1.7 \mathrm{~kg} \mathrm{~cm}^{-2}, 120{ }^{\circ} \mathrm{C}$ por $30 \mathrm{~min}$ ), conformado por tierra de bosque, perlita y arena en iguales proporciones. Las charolas con plántulas se transportaron al invernadero y durante 30 días se mantuvo el sustrato con una humedad relativa de 60-80\%; durante este período se aplicó una solución de Captan (2\%) cada cinco días para evitar la contaminación por hongos, posteriormente la humedad relativa se redujo al 50\%. La supervivencia se evaluó a los 90 días del establecimiento de las plántulas en el sustrato. Posteriormente, para seguir con su desarrollo, las plántulas se individualizaron y trasplantaron en bolsas de plástico de $15 \times 20 \mathrm{~cm}$ a los 180 días desde el inicio del experimento. Un esquema del método se presenta en la figura 1. 


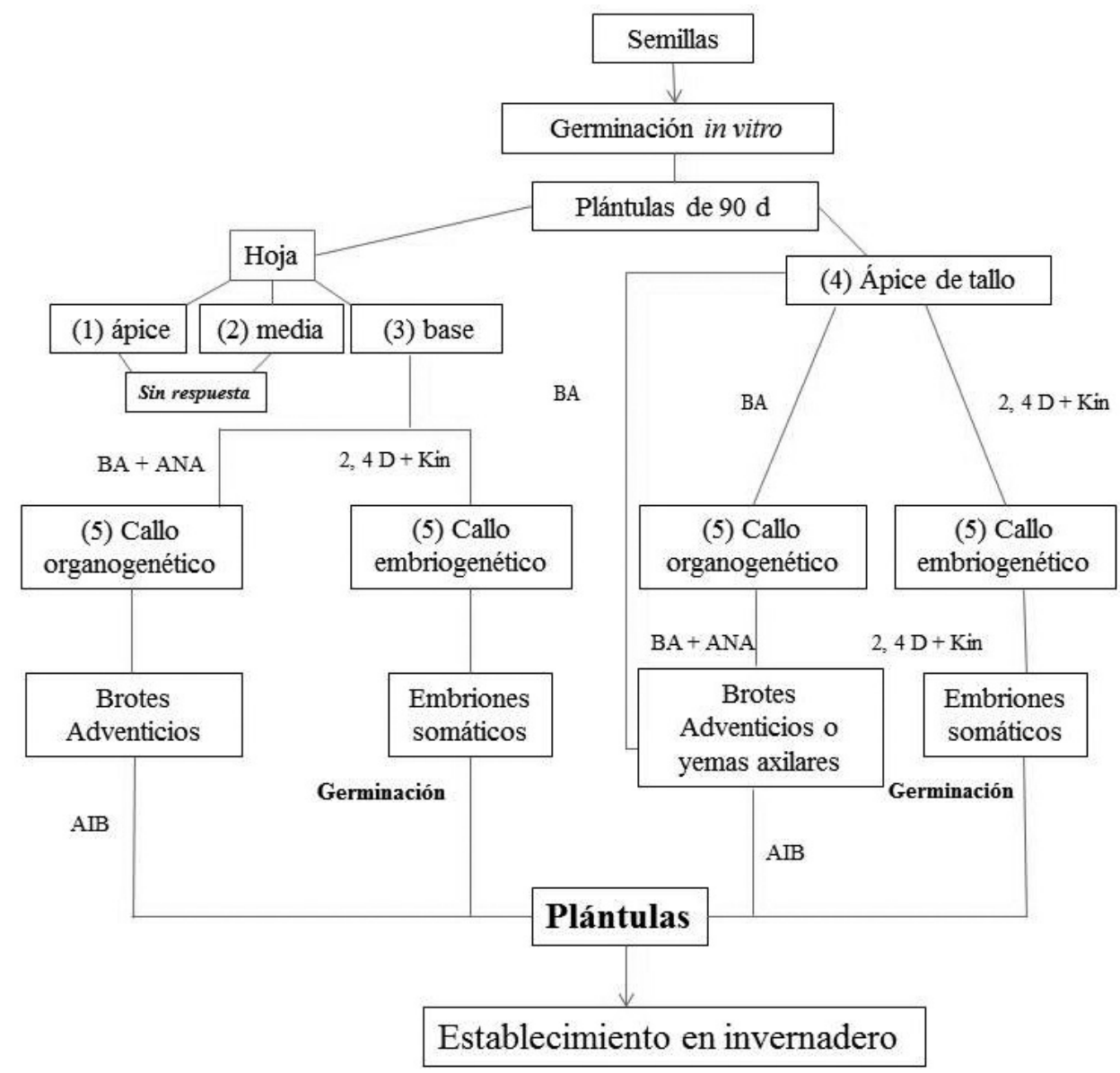

Figura 1. Método utilizado para la micropropagación de Beaucarnea inermis vía organogénesis y embriogénesis somática directa. A partir de la germinación in vitro se obtuvieron plántulas de las que se tomaron cinco tipos de explantes, que se sometieron a diferentes tratamientos hormonales. Las plántulas obtenidas se establecieron en invernadero.

Análisis estadístico. Se utilizó un diseño completo al azar. Los datos generados de los diversos tratamientos se analizaron de forma separada mediante un ANOVA de una vía, seguido de la prueba pos hoc de comparaciones múltiples Tukey-Kramer HSD (Honestly Significant Difference, por sus siglas en inglés), para verificar el efecto de los tratamientos en la generación de embriones somáticos, brotes, la longitud de raíz y supervivencia de las plántulas ex vitro. Los análisis fueron realizados con el programa estadístico SAS (SAS, 2000).

\section{Resultados}

Germinación de semillas in vitro. Después de 30 días de haber sembrado las semillas de Beaucarnea inermis, se registró 92\% de germinación, y se produjeron plántulas que a los 90 días se caracterizaron por la presencia de raíces y de 4 a 6 hojas.

Embriogénesis somática indirecta. En todos los explantes de hoja, cultivados en presencia de 2,4-D e incubados en luz, se observó la formación de callo en menos del 5\% de los fragmentos sembrados; además, desde el inicio de su formación este tenía un alto grado de necrosis, por lo que solo se realizaron las evaluaciones en los tratamientos que fueron incubados en oscuridad. En el explante de ápice y parte media de hoja la respuesta fue escasa e insignificante, con presencia de alto porcentaje de necrosis, por lo que también se descartó el registro. En los explantes basales de hoja incubados en oscuridad se observó la generación de callo (Figura 2A) y posteriormente la formación de embriones sobre su superficie. El análisis estadístico registró diferencias significativas $(P<0.0001)$ en el número de embriones somáticos producidos en los diferentes tratamientos aplicados. En el tratamiento $0.5 \mathrm{mg} \mathrm{L}^{-1}$ de KIN y $2 \mathrm{mg} \mathrm{L}^{-1}$ de 2 ,4-D se generó el mayor número de embriones: 2.2 fue el promedio por segmento (Cuadro 1, Figura 2C).

En ápices de tallo, la formación de embriones somáticos entre los diferentes tratamientos fue significativamente diferente $(P<0.0001)$. La mayor respuesta en cuanto a la formación de embriones y volumen de callo se registró en presencia de $0.5 \mathrm{mg} \mathrm{L}^{-1}$ de $\mathrm{KIN}+4 \mathrm{mg} \mathrm{L}^{-1}$ de 2,4-D, gene- 
Cuadro 1. Efecto inductor de 2,4-D y KIN en tres diferentes explantes de Beaucarnea inermis, para el desarrollo de callo y de embriones somáticos. Cultivo en oscuridad; evaluación en bases de hojas y ápices de tallo a 24 semanas. El cultivo del callo se generó de ápice de tallo en B5 con $0.5 \mathrm{mg} \mathrm{L}^{-1} \mathrm{KIN}$ y $4 \mathrm{mg} \mathrm{L}^{-1}$ 2,4-D. Sac = sacarosa, ES = embriogénesis somática, D.E. = desviación estándar. ANOVA, solo los tratamientos con respuesta fueron incluidos en el cuadro. Diferentes letras en la columna HSD indican diferencia significativa, $P<0.0001$ en los tres tipos de explantes. $+++: \geq 2 \mathrm{~cm}^{3} ;++$ : $0.5-1.9 \mathrm{~cm}^{3} ;+:<0.5 \mathrm{~cm}^{3}$.

\begin{tabular}{|c|c|c|c|c|c|c|}
\hline KIN (mg L-1) & 2,4-D (mg L-1) & $\operatorname{Sac}\left(\mathrm{g} \mathrm{L}^{-1}\right)$ & $\mathbf{N}$ & Media ES \pm D.E. & HSD & Callo \\
\hline \multicolumn{7}{|l|}{ Base de hoja } \\
\hline 0.5 & 2.0 & 30 & 12 & $2.2 \pm 1.1$ & a & ++ \\
\hline 0.5 & 1.0 & 30 & 12 & $1.0 \pm 0.9$ & $b$ & ++ \\
\hline 0.0 & 2.0 & 30 & 10 & $0.8 \pm 0.8$ & bc & + \\
\hline 1.0 & 2.0 & 30 & 11 & $0.6 \pm 0.5$ & bcd & + \\
\hline 1.0 & 8.0 & 30 & 10 & $0.5 \pm 0.7$ & bcd & + \\
\hline 0.5 & 4.0 & 30 & 10 & $0.4 \pm 0.5$ & bcd & + \\
\hline 1.0 & 1.0 & 30 & 10 & $0.4 \pm 0.7$ & bcd & + \\
\hline 0.0 & 1.0 & 30 & 10 & $0.3 \pm 0.7$ & bcd & + \\
\hline 0.5 & 0.5 & 30 & 12 & $0.3 \pm 0.5$ & bcd & + \\
\hline 0.0 & 8.0 & 30 & 8 & $0.3 \pm 0.5$ & bcd & + \\
\hline 1.0 & 4.0 & 30 & 9 & $0.2 \pm 0.4$ & bcd & + \\
\hline 1.0 & 0.5 & 30 & 10 & $0.2 \pm 0.4$ & bcd & + \\
\hline 0.0 & 4.0 & 30 & 11 & $0.1 \pm 0.3$ & $\mathrm{~cd}$ & + \\
\hline \multicolumn{7}{|c|}{ Ápice de tallo } \\
\hline 0.5 & 4.0 & 30 & 6 & $6.8 \pm 3.8$ & a & +++ \\
\hline 0.5 & 2.0 & 30 & 6 & $2.7 \pm 1.2$ & $b$ & ++ \\
\hline 0.0 & 8.0 & 30 & 8 & $1.6 \pm 0.9$ & $b$ & ++ \\
\hline 0.5 & 8.0 & 30 & 8 & $1.4 \pm 0.5$ & b & + \\
\hline 0.0 & 4.0 & 30 & 8 & $1.1 \pm 0.6$ & b & ++ \\
\hline 0.5 & 6.0 & 30 & 8 & $1.0 \pm 1.1$ & $b$ & + \\
\hline 0.0 & 2.0 & 30 & 6 & $0.8 \pm 0.8$ & $\mathrm{~b}$ & + \\
\hline 0.0 & 6.0 & 30 & 6 & $0.8 \pm 0.4$ & $b$ & + \\
\hline \multicolumn{7}{|l|}{ Callo } \\
\hline 0.5 & 2.0 & 60 & 12 & $3.6 \pm 3.0$ & a & ++ \\
\hline 0.5 & 2.0 & 40 & 8 & $2.8 \pm 1.2$ & a & ++ \\
\hline 0.5 & 2.0 & 80 & 10 & $1.6 \pm 1.1$ & $a b$ & + \\
\hline 0.0 & 0.0 & 60 & 8 & $0.0 \pm 0.0$ & $\mathrm{a}$ & + \\
\hline
\end{tabular}

rando un promedio de 6.8 embriones por ápice (Cuadro 1, Figura 2D).

Las réplicas de cultivo de base de hoja y de ápice de tallo, que fueron incubadas en presencia de luz en medio B5 con la adición de 2,4-D generaron callo (Figura 2A) y, posteriormente, de este surgieron raíces adventicias cortas y gruesas (Figura 2B). Datos no evaluados integrados en este trabajo.

Organogénesis indirecta y directa. La formación de brotes adventicios en el segmento basal de hoja entre tratamientos fue significativo $(P<0.0001)$. Los valores más altos $(2.7 \mathrm{y}$ 2.8 brotes por explante) se registraron con $2 \mathrm{mg} \mathrm{L}^{-1}$ de BA $+0.5 \mathrm{mg} \mathrm{L}^{-1}$ de ANA y en $6 \mathrm{mg} \mathrm{L}^{-1} \mathrm{de} \mathrm{BA}+0.5 \mathrm{mg} \mathrm{L}^{-1} \mathrm{de}$ ANA, respectivamente (Cuadro 2). La mejor respuesta de inducción de callo también se vio reflejada con la mayor respuesta a la formación de brotes.

En ápices de tallo se registraron diferencias entre tratamientos $(P<0.0001)$. La mayor respuesta de formación de brotes adventicios (15.7 brotes por ápice; Figura $2 \mathrm{E}$ ), se presentó cuando el medio contenía $2 \mathrm{mg} \mathrm{L}^{-1}$ de BA; esta concentración de fitohormona también favoreció la mayor inducción de callo (Cuadro 2).

Los cultivos de callo para la formación de brotes adventicios fue significativo $(P=0.006)$, se registraron hasta 11.3 brotes por segmento de callo cuando el medio contenía $2 \mathrm{mg} \mathrm{L}^{-1}$ de $\mathrm{BA}$ (Figura 2F); de igual forma, ese fue el tratamiento que registró la mayor formación de callo (Cuadro 2). No se observó un efecto claro de la sacarosa en la formación de brotes.

Germinación de embriones somáticos. El 91\% de los embriones somáticos cultivados derivó al desarrollo a planta (Figura 2G) y el 9\% se desdiferenció a callo.

Enraizamiento in vitro de brotes adventicios y de inducción directa del ápice de tallo. En todos los tratamientos se observó la formación de raíces; sin embargo, la mayor respuesta se presentó en los tratamientos con 0.5 y $1 \mathrm{mg} \mathrm{L}^{-1} \mathrm{de}$ AIB (Cuadro 3). 


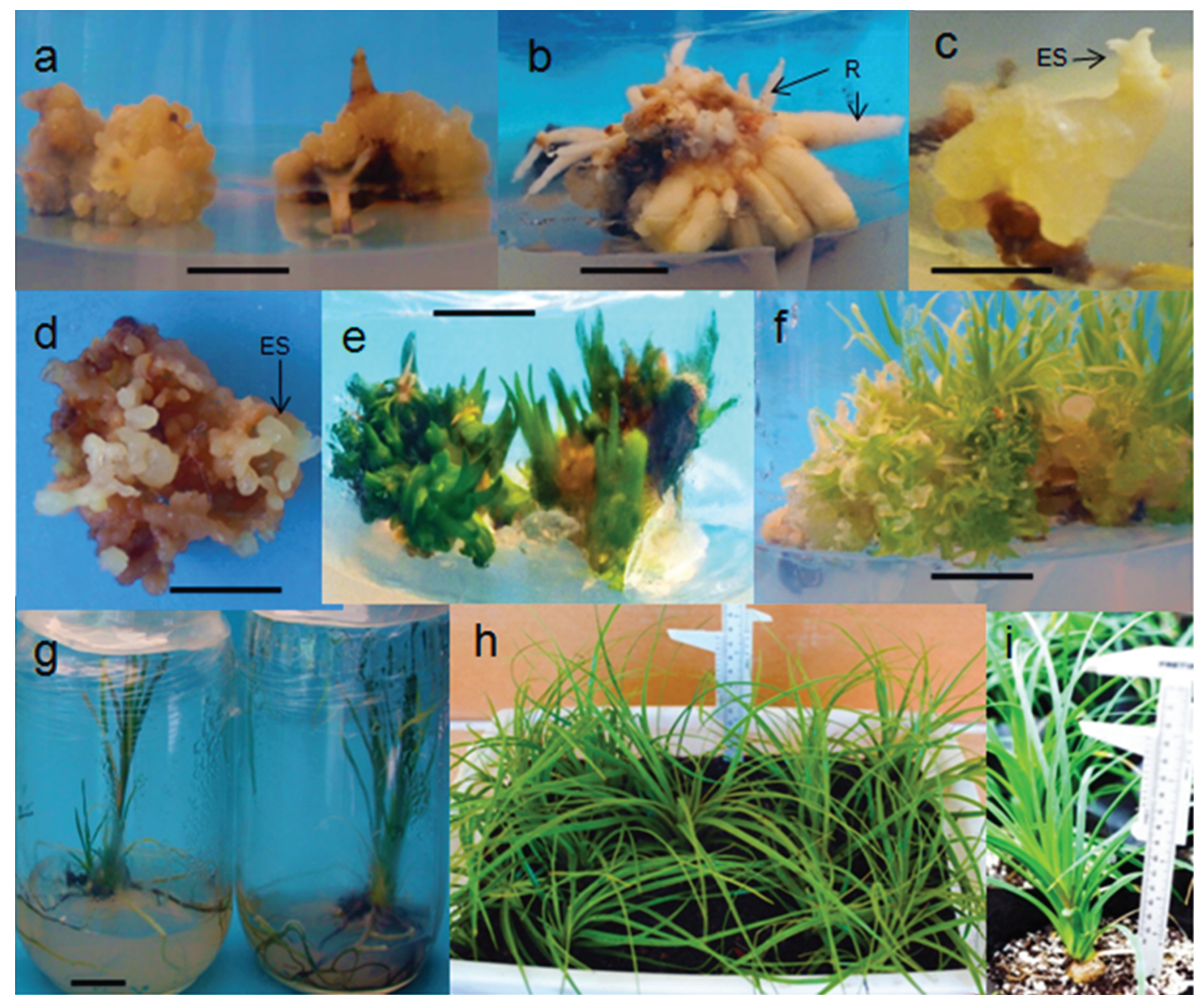

Figura 2. Micropropagación de Beaucarnea inermis. A) Inducción de callo en segmentos de hoja basal. B) Efecto del 2,4-D en callos de ápice de tallo en presencia de luz, se observan raíces adventicias, en las jóvenes y delgadas con pelos absorbentes. C) Embriogénesis somática de callo de hoja basal en ausencia de luz. D) Embriogénesis somática indirecta de ápice de tallo. E) Múltiples brotes en ápices de tallo. F) Brotes adventicios de callo derivado de ápice de tallo en presencia de $2 \mathrm{mg} \mathrm{L}^{-1}$ de BA. G) Enraizamiento y desarrollo de brotes in vitro. H) Establecimiento y desarrollo bajo condiciones de invernadero a los 90 días. I) Establecimiento y desarrollo bajo condiciones de invernadero a los 180 días. Barra en cultivo in vitro indica $1 \mathrm{~cm}$.

Adaptación de plantas en condiciones de invernadero. La supervivencia de plantas fue mayor del $96 \%$ y no se observaron diferencias significativas entre las enraizadas en medio básico y con AIB (Cuadro 3). Las plantas alcanzaron el estado juvenil después de 180 días de cultivo bajo condiciones de invernadero, y el $100 \%$ registró el ensanchamiento de la base del tallo o en forma de "cebolla" típica de estas plantas (Figura 2I).

\section{Discusión}

En este estudio se observaron altos porcentajes (92\%) de germinación in vitro en las semillas de Beaucarnea inermis. También bajo condiciones in vitro otros autores han registrado resultados similares (> 89\%) para B. gracilis y B. recurvata (Osorio-Rosales y Mata-Rosas, 2005; Reyes et al., 2013). Por otro lado, en un estudio de germinación in vivo realizado en $B$. gracilis, el porcentaje más alto registrado fue de 74\% (Flores y Briones, 2001). Los altos porcentajes de germinación observados in vitro podrían ser el resultado del suministro en cantidades óptimas y constantes de los factores ambientales más importantes en el proceso de germinación, como la humedad, temperatura, fotoperiodo, intensidad luminosa y nutrimentos (Baskin y Baskin, 1998). Una de las ventajas más importantes de las técnicas de cultivo in vitro es el control sobre los factores externos que determinan diferentes procesos fisiológicos. Golubov et al. (2007) reportaron porcentajes mayores al 80\% de germinación in vitro en semillas de $B$. recurvata que permanecieron almacenadas durante seis años en condiciones de baja temperatura $\left(6^{\circ} \mathrm{C}\right)$ y baja humedad relativa (en deshidratación con sílica gel). Bajo estas mismas condiciones de almacenamiento se documentó que las semillas de Agave victoriae-reginae pueden permanecer viables y sin variación en el porcentaje de germinación (96\%) por más de 15 años (Sierra.Yxta, 2009; Martínez-Palacios y Eguiarte, 2011). La germinación in vitro aunada al almacenamiento de semillas bajo condiciones específicas podrían presentarse como una 
Cuadro 2. Efecto inductor de BA y ANA en tres diferentes explantes de Beaucarnea inermis, para el desarrollo de callo y de brotes. Cultivo en fotoperiodo de16h luz; evaluación en base de hoja a las 22 semanas; ápice de tallo respuesta a las 8 semanas. El cultivo de callo se generó de ápice de tallo en medio MS con $2 \mathrm{mg} \mathrm{L}^{-1}$ BA. D.E. = Desviación Estándar. Diferentes letras en la columna HSD indican diferencia significativa, $P<0.0001$ (base de hoja y ápice de tallo), $P=0.006$ (callo). Para callo: +++: $\geq 2 \mathrm{~cm}^{3} ;++$ : 0.5-1.9 $\mathrm{cm}^{3} ;+:<0.5 \mathrm{~cm}^{3} ;-:$ ausencia.

\begin{tabular}{lccccc}
\hline $\begin{array}{l}\text { BA } \\
\text { mg L-1 }\end{array}$ & $\begin{array}{c}\text { ANA } \\
\text { mg L }\end{array}$ & N & $\begin{array}{c}\text { Media brotes } \\
\pm \text { D.E. }\end{array}$ & HSD & Callo $^{\mathbf{h}}$ \\
\hline \multicolumn{2}{l}{ Base de hoja } & & & & \\
6 & 0.5 & 9 & $2.8 \pm 2.6$ & $\mathrm{a}$ & +++ \\
2 & 0.5 & 11 & $2.7 \pm 1.2$ & $\mathrm{a}$ & ++ \\
6 & 0.1 & 8 & $1.8 \pm 1.2$ & $\mathrm{ab}$ & ++ \\
4 & 0.5 & 9 & $1.7 \pm 0.7$ & $\mathrm{ab}$ & ++ \\
4 & 0.1 & 7 & $1.1 \pm 0.7$ & $\mathrm{abc}$ & + \\
6 & 0.0 & 10 & $0.9 \pm 0.9$ & $\mathrm{bc}$ & + \\
2 & 0.1 & 10 & $0.0 \pm 0.0$ & $\mathrm{C}$ & - \\
4 & 0.0 & 12 & $0.0 \pm 0.0$ & $\mathrm{C}$ & - \\
2 & 0.0 & 12 & $0.0 \pm 0.0$ & $\mathrm{C}$ & - \\
0 & 0.0 & 10 & $0.0 \pm 0.0$ & $\mathrm{C}$ & - \\
0 & 0.5 & 12 & $0.0 \pm 0.0$ & $\mathrm{C}$ & - \\
0 & 0.1 & 12 & $0.0 \pm 0.0$ & $\mathrm{C}$ & - \\
Ápice de & tallo & & & & \\
2 & 0.0 & 15 & $15.7 \pm 4.4$ & $\mathrm{a}$ & +++ \\
4 & 0.0 & 10 & $4.0 \pm 2.9$ & $\mathrm{~b}$ & +++ \\
0 & 0.0 & 8 & $1.3 \pm 1.4$ & $\mathrm{~b}$ & ++ \\
8 & 0.0 & 9 & $0.2 \pm 0.4$ & $\mathrm{~b}$ & + \\
Callo & & & & & \\
2 & 0.0 & 35 & $11.3 \pm 8.9$ & $\mathrm{a}$ & +++ \\
2 & 0.1 & 18 & $5.4 \pm 2.2$ & $\mathrm{~b}$ & ++ \\
0 & 0.0 & 33 & $3.1 \pm 5.7$ & $\mathrm{~b}$ & + \\
3 & 0.1 & 20 & $3.1 \pm 1.8$ & $\mathrm{~b}$ & + \\
3 & 0.0 & 18 & $\geq 2.9 \pm 2.3$ & $\mathrm{~b}$ & + \\
\hline
\end{tabular}

alternativa de manejo en programas de conservación de especies, como lo han propuesto Golubov et al. (2007) para agaváceas y nolináceas.

La capacidad embriogénica de un cultivo depende de las características genéticas, el estado fisiológico y la edad de la planta donadora de los explantes (Gaj, 2004); así como del balance en la concentración de fitohormonas y las condiciones de incubación (Villalobos y Thorpe, 1991[AR5]). Sin embargo, se ha considerado que el factor más importante es el tipo de explante utilizado (Gaj, 2004). Para la inducción de la embriogénesis somática se han utilizado diversos tipos de explantes como: fragmentos de plántulas, peciolos, hojas, meristemos, semillas, cotiledones, raíces y embriones cigóticos inmaduros. Los embriones cigóticos inmaduros han resultado ser muy efectivos en especies en las que no se observó la inducción embriogénica con otro tipo de explantes (Raemakers et al., 1995; Gaj, 2004). En el caso de Beaucarnea inermis, los explantes utilizados provenían de hojas de plántulas, de las tres partes de hoja probadas (base, media y ápice), la base presentó la mejor respuesta. En numerosos estudios se ha registrado la eficacia en la inducción de embriogénesis somática utilizando hojas como explantes; sin em-
Cuadro 3. Efecto de IBA en la formación y crecimiento de raíces en brotes de Beaucarnea inermis y sobrevivencia de plántulas en invernadero. $N=27$, enraizamiento in vitro. Resultado a las cuatro semanas de cultivo in vitro. D.E. = Desviación Estándar. Diferentes letras indican diferencia significativa en la columna HSD, $P<0.0001$. ${ }^{190}$ días después de establecidas bajo condiciones de invernadero, sin diferencia significativa.

\begin{tabular}{cccccc}
\hline $\begin{array}{c}\text { IBA } \\
\left(\mathbf{m g} .^{-1}\right)\end{array}$ & $\begin{array}{c}\text { Brotes con } \\
\text { raíz (\%) }\end{array}$ & $\begin{array}{c}\text { Media de } \\
\text { longitud de } \\
\text { raíz }(\mathbf{m m}) \\
\pm \text { D.E. }\end{array}$ & HSD & N & $\begin{array}{c}\text { Sobre- } \\
\text { vivencia } \\
\text { ex vitro } \\
(\%)\end{array}$ \\
\hline 1.0 & 96.3 & $11.6 \pm 9.6$ & a & 26 & 100 \\
0.5 & 96.3 & $8.6 \pm 5.9$ & a & 26 & 100 \\
0.0 & 92.6 & $3.2 \pm 0.6$ & b & 25 & 96 \\
\hline
\end{tabular}

bargo, en este estudio se encontró que no todas las partes de la hoja tienen la misma capacidad embriogénica. RodríguezGaray et al. (1996) reportaron la inducción de embriogénesis somática en Agave victoriae-reginae utilizando segmentos de hoja basal como explantes en medio suplementado con 2, 4-D; sin embargo, los resultados fueron diferentes cuando se utilizaron hojas completas de plántulas generadas in vitro, en este caso se observó la formación de callo con nódulos en su superficie (Martínez-Palacios et al., 2003); por lo que los explantes provenientes de hoja, particularmente del área de la hoja unida al tallo, parecen ser los que muestran la mayor respuesta de embriogénesis somática.

La presencia de luz en la morfogénesis in vitro puede dar una respuesta contrastante con relación a cuando está ausente. La interacción de la luz y 2,4-D en los explantes de Beaucarnea inermis indujo la formación de callo y posteriormente la formación de raíces adventicias, con pelos absorbentes en las raíces jóvenes y delgadas. En contraste, la incubación en oscuridad indujo en el callo la formación de embriones somáticos. El efecto de la luz en interacción con auxinas en la inducción de formación in vitro de raíz ha sido reportado para otras especies (Zimmerman, 1984; Hansen, 1987[AR6]; van der Krieken et al., 1992); empero, la razón de la respuesta observada aún se desconoce. A diferencia de nuestros resultados, en Agave victoriae-reginae, la presencia de luz y 2,4-D no indujo la formación de raíces adventicias en el cultivo de callo y tampoco afectó a la formación de embriones somáticos adventicios (Martínez-Palacios $e t$ al., 2003). La diferencia en la respuesta morfogenética con luz y en oscuridad observada en $B$. inermis parece ser específica; no obstante, es recomendable que esto sea evaluado con otras especies del mismo género.

La adición de BA en el medio de cultivo sola o en combinación con bajas concentraciones de ANA, promovió el desarrollo de brotes adventicios en hojas, callo y en ápices de tallo de Beaucarnea inermis, resultados similares reportaron Osorio-Rosales y Mata-Rosas (2005) en B. recurvata y, Reyes et al. (2013) en B. goldmanii, B. gracilis y B. recurvata al adicionar BA al medio de cultivo. Asimismo, en muchas especies hortícolas y de interés económico, como 
orquídeas, se ha utilizado la BA para inducir la formación de brotes adventicios. La BA pertenece al grupo de las citocininas, que son las hormonas clave para la inducción de brotes en diversos tejidos y órganos, como hojas, raíces, médula y cotiledones, en combinación con las auxinas, estimulan la formación de callo (Howell et al., 2003). La BA también se ha utilizado con fines de conservación en Agave victoriae-reginae, donde indujo la organogénesis somática en tallos (Martínez-Palacios et al., 2003). Por lo que la BA se presenta como un potente inductor de brotes ya probado en diversas especies y que puede ser aplicado en $B$. inermis como una estrategia en los protocolos de conservación.

La adición de AIB al medio de cultivo favoreció la formación de raíces en brotes de Beaucarnea inermis; sin embargo, en el tratamiento sin fitohormonas también se observó la formación de raíces aunque en menor proporción. Estos últimos resultados coinciden con lo registrado en $B$. gracilis y $B$. recurvata, donde se observó el enraizamiento de más del 60 y $80 \%$ de los brotes cultivados en medio MS sin la aplicación de fitohormonas (Samyn, 1997; Osorio-Rosales y Mata-Rosas, 2005). En Opuntia sp., la adición de AIB aceleró la formación de raíz en los explantes (Escobar et al., 1986). A pesar de los mejores resultados observados en $B$. inermis, en cuanto a la formación de raíces con la aplicación de AIB, es recomendable usar las concentraciones más bajas donde se registre el inicio del efecto, esto tendrá que ajustarse a cada especie para evitar desarrollos fisiológicos anormales de raíces y plantas (Martínez-Palacios et al., 2003). Aunque las fitohormonas no son caracterizadas por inducir mutaciones, su uso en altas concentraciones acelera los procesos de división celular, en los cuales se pueden generar variaciones genéticas (George et al., 2008). En Bletia urbana y en otras orquídeas, al utilizar ANA en concentraciones que van de $1 \mathrm{mg} \mathrm{L}^{-1}$ o mayores, se ha observado la inducción de raíces morfológicamente anormales con epidermis lisas y sin pelos absorbentes, que son poco funcionales durante su establecimiento en suelo. De acuerdo a Martínez-Palacios (1991), este problema se resuelve cuando en su nuevo ambiente, de la base del tallo de la planta se generan nuevas raíces. En Agave victoriae-reginae, la aplicación de la citocinina BA en concentraciones de $2 \mathrm{mg} \mathrm{L}^{-1}$ o mayores durante el desarrollo de plántulas in vitro, era notable la producción de hojas más cortas y anchas en relación con los cultivos de los tratamientos de control (Martínez-Palacios, 1998; MartínezPalacios et al., 2003).

\section{Conclusiones}

Los resultados generados en Beaucarnea inermis muestran que el establecimiento de plantas vía organogénesis y embriogénesis somática, pueden ser implementadas en principio de manera exploratoria, evaluando costos y beneficios como un protocolo que podría satisfacer las demandas comerciales actuales. Se debe tomar en cuenta que los tiempos y costos de producción de plantas in vitro se reducen considerablemente cuando se cuenta con material vegetal en proceso de multiplicación o con respuesta morfogénica inducida. El uso industrial de esta técnica y el control más estricto en los sistemas de manejo o saqueo de material biológico en poblaciones silvestres evitará la extinción de la especie.

\section{Agradecimientos}

Los autores agradecen el apoyo financiero del Consejo Nacional de Ciencia y Tecnología (Proyecto CONACyT-SEP P47777Z, Proyecto 5.6 CIC-UMSNH) y a los revisores anónimos que enriquecieron el manuscrito.

\section{Literatura citada}

Baskin C.C. y Baskin J.M. 1998. Seeds: Ecology, Biogeography, and Evolution of Dormancy and Germination. Academic Press, San Diego.

Cardel Y., Rico-Gray V., García-Franco J.G. y Thien L.B. 1997. Ecological status of Beaucarnea gracilis, an endemic species of the semiarid Tehuacán Valley, México. Conservation Biology 11:367-374.

Gaj D.M. 2004. Factors influencing somatic embryogenesis induction and plant regeneration with particular reference to Arabidopsis thaliana (L.) Heynh. Plant Growth Regulation 43:27-47.

Escobar H.A., Villalobos A.V.M. y Villegas M.A. 1986. Opuntia micropropagation by axillary proliferation. Plant Cell Tissue and Organ Culture 7:269-277.

Flores J. y Briones O. 2001. Plant life-form and germination in a Mexican inter-tropical desert: effects of soil water potential and temperature. Journal of Arid Environments 47:485-497.

Gamborg O.L., Miller R.A. y Ojima K. 1968. Nutrient requirements of suspension cultures of soybean root cells. Experimental Cell Research 50:151-158.

George E.F., Hall M.A. y De Klerk G.J. 2008. Plant Propagation by Tissue Culture. $3^{\mathrm{a}}$ ed. Springer, Dordrecht.

Golubov J., Mandujano M.C., Arizaga S., Martínez-Palacios A. y Koleff P. 2007. Inventarios y conservación de Agavaceae y Nolinaceae. En: Colunga-García M.P., Larqué S.A., Eguiarte L.E. y Zizumbo-Villareal D. Eds. En lo Ancestral hay Futuro: del Tequila, los Mezcales y otros Agaves, pp. 133-152, Centro de Investigación Científica de Yucatán, A.C., Consejo Nacional de Ciencia y Tecnología, Comisión Nacional para el Conocimiento y Uso de la Biodiversidad, Instituto Nacional de Ecología, México, D.F.

Hansen J. 1987. Stock plant lighting and adventitious root formation. HortScience 22:746-749.

Hernández L. 1993. Cladistic analysis of the American genera of Asparagales and the systematic study of Beaucarneae (Nolinaceae) and Hemiphylacus (Hyacinthaceae). Tesis Doctoral, Universidad de Texas, Austin. 201 pp.

Hernández S.L., Osorio R.M.L., Orellana L.R., Martínez M., Pérez F.M.A., Contreras H.A., Malda B.G., Espadas M.C., Almanza R.K.E., Castillo G.H.A. y Félix A.A. 2012. Manejo y Conservación de las Especies con Valor Comercial de Pata de Elefante (Beaucarnea). Universidad Autónoma de Querétaro, Querétaro. 
Howell S.H., Lall S. y Che. P. 2003. Cytokinins and shoot development. Trends Plant Science 8:453-459.

Irish M. y Irish G. 2000. Agaves, Yuccas, and Related Plants. A Gardener's Guide. Timber Press, Portland.

Lemaire C. 1861. Plantes recommandées. L'Illustration Horticole 8:t.289.

Martínez-Palacios A. 1991. Propagación masiva in vitro y recuperación de poblaciones de orquídeas en peligro de extinción. Tesis de Maestría en Ciencias (Biología), Facultad de Ciencias, Universidad Nacional Autónoma de México, México, D.F. 100 pp.

Martínez-Palacios A. 1998. Evaluación genética y demográfica de Agave victoriae-reginae T. Moore y aplicación del cultivo de tejidos para su conservación. Tesis de Doctorado en Ciencias, Facultad de Ciencias, Universidad Nacional Autónoma de México, México, D.F. 163 pp.

Martínez-Palacios A. 2012. Aspectos sobre el Manejo y Conservación de Agave Mezcalero en Michoacán. Coordinadora Nacional Fundaciones Produce, Universidad Michoacana San Nicolás de Hidalgo, Coordinadora Estatal de Ciencia y Tecnología de Michoacán, Morelia.

Martínez-Palacios A., Ortega-Larrocea M.P., Chávez V.M. y Bye R. 2003. Somatic embryogenesis and organogenesis of Agave victoriae-reginae: considerations for its conservation. Plant Cell, Tissue and Organ Culture 74:135-142.

Martínez-Palacios A. y Eguiarte. L.E. 2011. Agave victoriae-reginae T. Moore (Agavaceae): die Wildpopulationen und deren genetische Differenzierung. Avonia 29:139-145.

Martínez-Vázquez O. y Rubluo A. 1989. In vitro mass propagation of the near-extinct Mammillaria san-angelensis Sánchez-Mejorada. Journal of Horticultural Science 64:99-106.

Mora J.L. 2005.[AR7] Importancia y distribución del sollate (Beaucarnea inermis) en el estado de Tamaulipas y Noreste de San Luis Potosí. Tesis de Maestría, Unidad Académica Multidisciplinaria de Agronomía y Ciencias, Universidad Autónoma de Tamaulipas. Ciudad Victoria. 65 pp.

Murashige T. y Skoog F. 1962. A revised medium for rapid growth and bioassays with tobacco tissue culture. Physiologia Plantarum 5:473-497.

Murashige T. 1978. The impact of plant tissue culture on agriculture. En: Thorpe T.A. Ed. Frontiers of Plant Tissue Culture, pp 15-26, International Association of Plant Tissue Culture, Calgary.

Osorio-Rosales M.L. y Mata-Rosas M. 2005. Micropropagation of endemic and endangered Mexican species of ponytail palms. HortScience 40:1481-1484.

Pérez-Farrera M.A., Hernández-Sandoval L., López-Cruz A., Espinosa-Jiménez J.A., López S., Zenteno-Cruz G. y Gómez-Domínguez H. 2012. Estructura, densidad poblacional y relacio- nes alométricas de Beaucarnea goldmanii Rose y Beaucarnea sanctomariana L. Hern. (Asparagaceae) en Chiapas y Oaxaca, México. Lacandonia 6:7-17.

Raemakers C.J.J.M., Jacobsen E. y Visser R.G.F. 1995. Secondary somatic embryogenesis and applications in plant breeding. Euphytica 81:93-107.

Reyes S.A.I., Morales M.C.F., Pérez R.M.E. y Pérez M.B.E. 2013. Propagación in vitro de Nolináceas mexicanas. Investigación y Ciencia 21:12-20.

Rodríguez-Garay B., Gutiérrez-Mora A. y Acosta-Dueñas B. 1996. Somatic embryogenesis of Agave victoria-reginae Moore. Plant Cell, Tissue and Organ Culture 46:85-87.

Rubluo A., Chávez V., Martínez P.A. y Martínez-Vázquez O. 1993. Strategies for recovery of endangered orchids and cacti through in vitro culture. Biological Conservation 63:163-169.

Samyn G. 1997. Micropropagation of Beaucarnea recurvata Lem. Syn. Nolina recurvata (Lem.) Hemmsl. (ponytail palm). Biotechnology in Agriculture and Forestry 40:264-275.

Sarasan V. Cripps R., Ramsay M.M., Atherton C., McMichen M., Prendergast G. y Rowntree J.K 2006. Conservation in vitro of threatened plants - Progress in the past decade. In Vitro Cellular and Developmental Biology Plant 42:206-214.

SAS. 2000. JMP. Statistic and Graphics Guide. Version 4. SAS Institute, Inc., Cary.

SEMARNAT. Secretaría de Medio Ambiente y Recursos Naturales. 2010. Norma Oficial Mexicana NOM-059-SEMARNAT-2010, Protección ambiental-Especies nativas de México de flora y fauna silvestres-Categorías de riesgo y especificaciones para su inclusión, exclusión o cambio-Lista de especies en riesgo.

Sierra-Yxta M.L. 2009. Dinámica del banco de semillas de tres especies de Agave spp. para evaluar su potencial de conservación ex situ. Tesis de licenciatura, Facultad de Biología, Universidad Michoacana de San Nicolás de Hidalgo. Morelia. 39 pp.

Thorpe T.A. 2006. History of plant tissue culture. En: Loyola-Vargas V.M. y Vázquez-Flota F. Eds. Plant Cell Culture Protocols. Methods in Molecular Biology. Vol. 318. 2a ed., pp 9-32. Humana Press Inc., Totowa.

van der Krieken W.M., Breteler H., Visser M.H.M. y Jordi W. 1992. Effect of light and riboflavin on indolebutyric acid-induced root formation on apple in vitro. Physiologia Plantarum 85:589-594.

Villalobos A.V.M. y Thorphe T.A. 1991. Micropropagación: conceptos, metodología y resultados. En: Roca W.M. y Mroginski L.A. Eds. Cultivo de Tejidos en la Agricultura: Fundamentos y Aplicaciones. [AR9]Pp. 127-141. CIAT, Cali.

Zimmerman R.H. 1984. Rooting apple cultivars in vitro: interactions among light, temperature phloroglucinol and auxin. Plant Cell Tissue and Organ Culture 3:301-311.

Recibido: 26 de marzo de 2014

Aceptado: 11 de agosto de 2014 